\title{
A Critical Perspective of Leadership Theories
}

\author{
http://doi.org/10.21272/bel.5(1).57-65.2021
}

Sivanathan Sivaruban, ORCID: https://orcid.org/0000-0001-8280-1183

MBA (Aus), FCMA, B. Com (Spl), CPA PNG, HNDA, MAAT, Senior Lecturer, International Training Institute, Port Moresby, Papua New Guinea

\begin{abstract}
This paper summarizes leadership theories and critically analyzes the different viewpoints on leadership theory in the real corporate world. The main purpose of the study is to examine leadership theories from a critical perspective in a practical context. The systematization of the literature sources and study approaches for solving the problem on a practical perspective toward leadership theories that indicate leadership theories are emerging research topics in the dynamic environment. The relevance of this critical perspective on leadership theories is redesign leadership style based on the current business environment. Investigation of the leadership theories from a critical perspective is conducted in the following logical sequence, such as the introduction, literature review, methodological tools of the research, analysis of each leadership theory, results, discussion, and conclusion of the study. The paper presents the outcome of an empirical analysis on a critical perspective of leadership theories, which showed that leadership theories have not yet been combined. The research empirically confirms that leadership theories prove that the outcome of the study can be a critical tool for future researchers, industry practitioners and other related stakeholders to redesign the leadership style to suit the competitive business environment. The result of the research can be useful to provide significant implications and insights into the leadership theories. A critical analysis of those theories shall enlighten the literature review of leadership theories and redesign leadership style to create a new set of leadership theories since no universal leadership style is accepted in the world. Finally, the leadership style has shifted to another dimension in emotional intelligence due to COVID-19, the global pandemic, creating a new set of attributable skills such as good listening skills, resilience, collaboration, and empathy. COVID-19 has developed a unique leadership style called resilient style.
\end{abstract}

Keywords: Behavioral Theory, Contingency Theory, Leadership, Path-Goal Theory, Trait Theory.

JEL Classification: M10, M12.

Cite as: Sivaruban, S. (2021). A Critical Perspective of Leadership Theories. Business Ethics and Leadership, 5(1), 57-65. http://doi.org/10.21272/bel.5(1).57-65.2021.

Received: 20 February 2021

Accepted: 23 March 2021

Published: 30 March 2021

Copyright: (C) 2021 by the author. Licensee Sumy State University, Ukraine. This article is an open access article distributed under the terms and conditions of the Creative Commons Attribution (CC BY) license (https://creativecommons.org/licenses/by/4.0/).

\section{Introduction}

Scholars have defined leadership and key terms used in the definitions of leadership are goals, inspiring others, decisive actions and focus for the foreseeable future, etc. This study is a critical analysis of leadership theories developed based on various scholarly comments and the recent emergence in global business leadership style. The theories are developed throughout periods and new philosophical leadership theories are consistently emerging due to the rapid changes in the business environment worldwide. In developing the study, various leadership theories are selected for the analysis. The pioneer leadership theory known as the great man theory was developed in 1840, and all other theories were developed based on the first leadership theory. The trait theory indicated that leadership characteristics could be gained and learned, but not from birth heredity whereas, effective leadership behavior depends on the best behaviors at a particular time. Still, the same behavior has not been always effective in the behavioral theory. Different leadership styles require different situations in which effective leadership style must change in line with environmental factors or according to the situation in the dynamic business environment. The leader uses the power and authority to influence the followers to accomplish the vision of the organization by using various leadership techniques. The leadership theories were developed based on the situation and competencies in the dynamic environment. Many leadership theories have been developed to build new leadership theories based on the competitive environment. Leadership requests a more holistic approach in corporate governance. Leadership is the most popular research topic among different disciplines. The numbers of research and publication on leadership 
have dramatically increased recently to help build the new leadership theory. The various leadership theories have been developed over a period. These theories have been analyzed and criticized by various academics and theoreticians, but the leadership theories have not been combined to create a new single leadership style yet. The result of the study is to enhance the leadership literature review and concludes that no universal leadership style is accepted in the world.

\section{Literature Review}

This study will critically analyze three leadership theories such as trait theory, behavioral theory and contingency theory. Most literature reviews were conducted for the leadership theories based at different periods, which hassled to new leadership theories based on the weakness of the previous leadership theories. As part of the literature review, the great man theory and trait theory are the same leadership theories; however, both leadership theories are different in the actual context. In this perspective, "leadership is of high interest in terms of studies" (Bennis, 2007) due to humans' involvement. It is noted that "leadership theory has not yet been integrated" (Avolio, 2007). The great man theory is the first leadership and pioneer theory written in 1841. The great man theory and trait theory have been criticized due to the lack of scientific evidence and inequity in gender. The behavioral theory has not considered situational factors in the effective leadership style; the contingency theory is based on its North American origins. All three leadership theories have been criticized from different perspectives. In this respect, "leadership is a process where an individual influences a group of individuals to achieve a common goal" (Northhouse, 2010). The success of any entity depends on the collaboration of competent leaders and staff as it is the leadership of managing people of distinct qualification compared with others. Successful leaders should have the critical skills to lead the organization in the right direction. Burns (1978) pointed out that leadership is one of the most observed phenomena on earth but the least understood. Leadership style can inspire people and accomplish goals without hindrance. Leaders mobilize employees toward commitment (Gardner, 1990). Leader style can be an influencing factor to the employees and finally to their success or failure. Leadership is a powerful tool to accomplish goals at different stakeholders' perspectives. Ineffective leadership is the major reason for the decline in industrial productivity and North American corporations' downward positioning globally (Wallace \& Weese, 1995).

\section{Methodology and Research Methods}

The research objective is a critical perspective of leadership theories and supports existing leadership to develop a new set of leadership theories to suit the competitive business environment. The empirical study shall confirm the existing literature review of leadership theories based on the proper explanation of the research findings. A critical perspective of leadership theories is based on secondary data such as published journals, books, website searches, and articles. The author of this study has been working in Papua New Guinea for the last 13 years. He has been widely used his knowledge and experience on the subject matters to write this research. No formal research has been conducted for this study. The author used descriptive analysis to identify, re-assess critical analysis from different leadership theories. The empirical survey of leadership theories such as trait theory, behavioral theory and contingency theory has been used to conduct the study of different perspectives. The outcome of the survey can enlighten on the existing literature review in leadership theories.

\section{Trait Theory}

The trait theory has emerged due to criticisms of the great man theory. The main assumption of the great man theory was that the leader has natural characteristics or inherited features to take the lead of the entity, and further, the theory argues that leaders are born. The trait theory assumed that leadership characteristics could be gained and learned but not inherited. In this context, "the trait theory is considered a modification of the great man theory" (Kirkpatrick and Locke, 1991). The leader should have distinguished features to compare with other persons. The trait theory has summarized the three main factors as physical factors, ability, and personality factors for an effective leader. The trait theory was developed based on several typical personality features such as traits and quality. This theory can also help leaders develop personality features to be effective leaders in the competitive environment. Overall traits are "height, weight, gender, maturity, openness, persuasion, domination, knowledge, determination, self-confidence and forward vision is just some of them" (Harrison, 2018; Stodgill, 1974). The trait features originating from the external trait features can enter our minds to create an effective leadership style throughout internal beliefs and processes. Zaccaro's model (2004) has created the following trait theory-leadership model (Figure 1). 


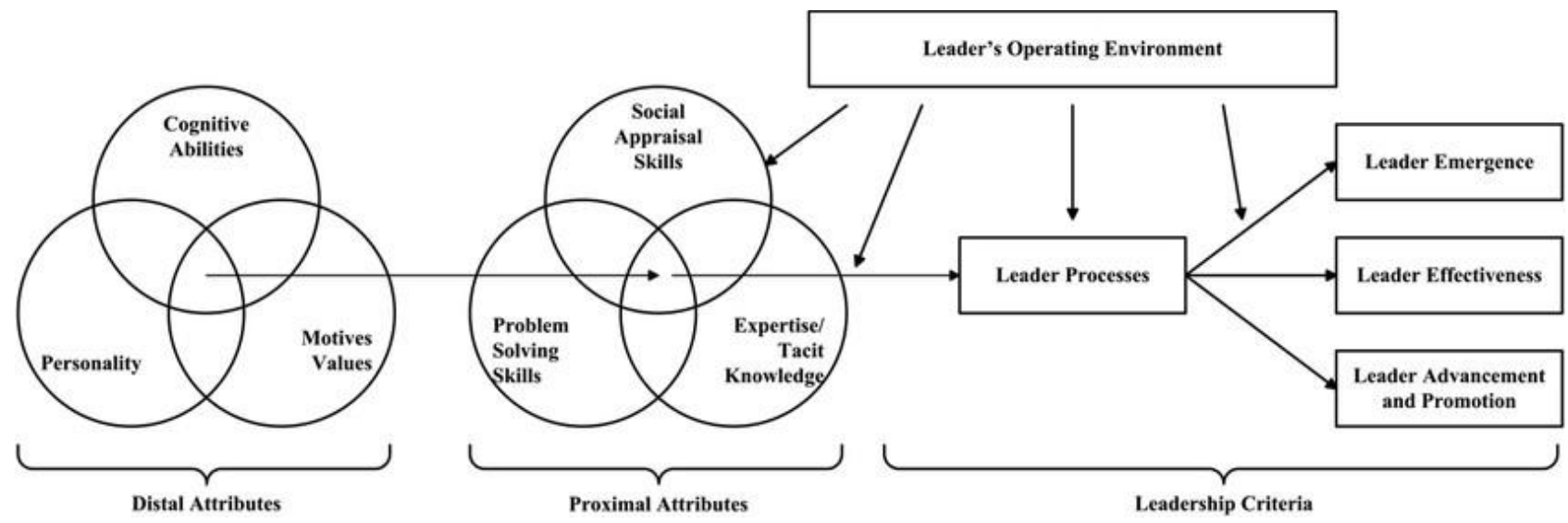

Figure 1. Traits of leader based on Zaccaro Model (2004)

Source: Zacccaro, S. J., 2004. Trait-Based Perspectives of Leadership. American Psychologist ,62(1), 6.

Figure 1 shows that leader processes were developed from the distal and proximal attributes. A leader's operating environment is in the proximal points and leadership processes that can create emergence, effectiveness, advancement, and leaders' promotion. The great man theory and trait theory have common assumptions, but both theories are different. The main criticism in the trait theory is the lack of empirical test research (Harrison, 2018). In this perspective, the trait theory is not based on the scientific method, but it is based on personal characteristics developed through continuous professional training and development. The trait features originating from the external can enter our minds to create an effective leadership style throughout internal beliefs and processes. In this perspective, some researchers are concerned about external physical characteristics, but others focus on internal minds, such as intelligence, self-confidence, and willpower. The trait theory has failed to provide "clear information in the measurement of characteristics" (Bolden et al., 2006). The theory failed to provide detailed information on measuring degree of leader traits where no solid decision can be made. In this context, the theory has provided common traits for an effective leader. However, the common traits cannot be a successful leader. The trait can be one factor that the best leader cannot determine. In recent research, "the factors leading to the leader's achievement in some studies have led to failure in other studies" (Fleeor, 2006). The trait theory is simplistic (Northouse, 2015) and, the "predictable nature of the leader's behavior is less effective, and their traits are not necessarily effective and consistent in all situations and cases" (McCleskey \& Allen, 2014). In recent studies, "there is no trait that would guarantee leadership success as the attributes are related to leadership behavior and effectiveness" (Yukl, 2002). The trait theory does not consider the whole business environment factors to conclude. The future study can explore trait theory in different perspectives such as physical and internal features, common traits and other attributes skills.

\section{Behavioral Theory}

The best leader can be identified based on his/her behavior. No leader behavior is innate, but can be learned through experience (Goff, 2003). Behavioral theory has reported that the change in the leader's behavior can be continuous learning and not from the inherited characteristics. An effective leader's behavior theories have developed due to the great man and trait theories' failure. The "effectiveness of a leader is related to how the leader behaves or what he/she does" (Northhouse, 2010). In this perspective, leadership can bring success to the organization by the delegation of the task and a proper channel of communication between subordinates. Effective leadership behavior depends on the best behaviors at a particular time, but the same behavior has not been always effective. Nevertheless, the "behavioral theory's main criticism is that it does not consider situational factors in leadership" (Barling et al., 2011; Harrison, 2018). The leader will decide the best behavior approach based on the situation and the leader cannot follow the same process in all cases. As a result, the effects of leadership behavior depend on different conditions. The behavior of leadership characters is developed through lifelong learning and work experience. The following are behavioral theories with findings.

\begin{tabular}{|c|c|}
\hline Behavioral Theories & Findings \\
\hline Lowa University studies & Democratic leadership \\
\hline Ohio University studies & Relationship and Task oriented \\
\hline Michigan University studies & Employee-oriented leadership \\
\hline Blake and Mouton managerial diagram model & Team management or Team leadership \\
\hline
\end{tabular}

Figure 2. Summary of behavioral theory findings

Source: Compiled by the author 
The above figure 2 shows that behavioral theories findings have inconsistencies like trait theory so contingency theory was developed to overcome the weakness in the trait and behavioral theories.

\subsection{Lowa University Studies by Kurt Lewin and Friends}

In research studies conducted during the 1930s at Iowa State University, three leadership styles were identified, which are "autocratic, democratic and laissez-faire" (Bryman, 1986). Effective leadership styles depend on the leader's behavior. An autocratic leader tends to centralize authority and derive power from the position, control of rewards, and coercion (Daft, 1999). An authoritarian leader is more suitable for the disciplinary forces and in the task-orientated entity. An autocratic leadership style can be more ideal for a short period creating a successful result. However, some scholars argue that an authoritarian leader can apply certain circumstances to achieving production targets within the time frame. Kurt Lewin and his team-conducted research in the mask-producing organization under the autocratic leadership style have seen the production volume increase in the short term (Billing, 2015). A democratic leader delegates authority to others, encourages participation, relies on subordinates' knowledge to complete tasks, and depends on respect for the subordinate influence (Daft, 1999). A democratic leader can be an effective leader in behavior for the long-term success of the organization. The democratic leader is more concerned about the employees' human relation skills in the organization and will plan to involve the employees in decision-making processes. Laissez-faire is the absence or avoidance of leadership and has been labeled the most ineffective style (Bass, 1990a). Under the liassezfaire leadership style, employees are never-interfered or intervened with (Harrison, 2018). Therefore, in the long period, democratic leadership style behavior can be the best leadership style.

\subsection{Ohio State Leadership Studies}

Ohio State studies were observed as necessary because the research dealt with the "activities of leaders, instead of traits" (Bryman, 1986). The Ohio State studies have found that leadership behavior is based on employeeoriented and task-oriented. Both factors are independent and can be applied simultaneously. In this respect, "consideration refers to the need for our understanding of human relations and is related to employee's needs" (Griffin, 1990; Schriesheim et al., 2001). Another factor, "the job-oriented refers to the task while dealing with the entity's needs" (Daft et al., 2010; Gordon, 1991). Hence, the best leadership style can be high-level relationship-oriented and task-oriented based on the situation, but both factors cannot be at a high level in the practical context. The higher-level leadership style is on the relationship, while task-oriented was later pronounced a myth; it was too simple (Bartol \& Martin, 1998).

\subsection{Michigan University Studies}

Leadership research studies during the 1940s conducted at the University of Michigan compared the "behavior of effective and ineffective leaders" (Leftwich, 2001). These studies have found that the two factors, such as the employee-centered and job-centered are similar to the Ohio State leadership studies; however, the only difference is that the leadership can be used in one leadership style at a time. The employees-centered is a concern for each employee's needs and well-being, while job-centered "focuses on reaching goals and facilitating the structure of tasks" (Leftwich, 2001).

\section{Michigan Studies}

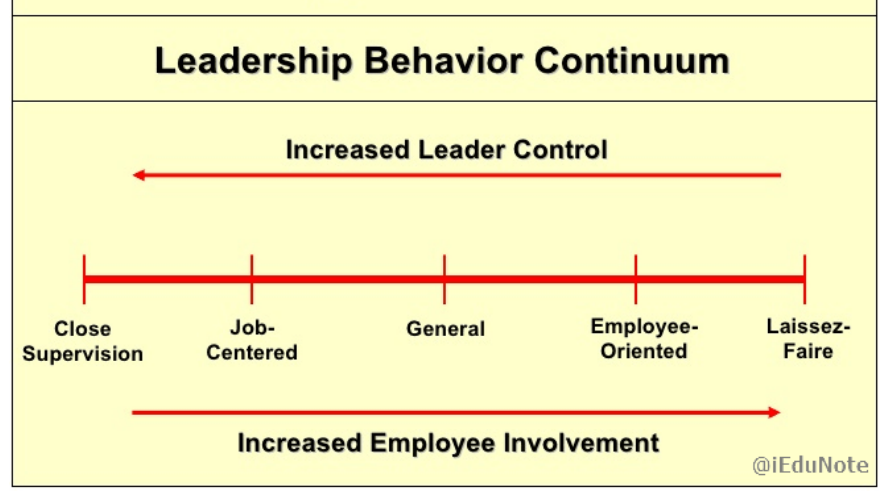

Figure 3. Michigan studies

Source: https://www.iedunote.com/michigan-leadership-studies accessed on February 4, 2021 
Studies have found that the leader can be used in one type of leadership, but he/she cannot change the leadership style based on the levels of the employees 'competency (Hughes, 2004). In these studies, the best leader can consider the task-oriented approach to achieve the production target, while at the same time, he/she can also view the employees' relationship to keep the team at the satisfaction level (Figure 3). It can be a difficult task in a practical context, but the leader can maintain a moderate level for both factors to achieve the best results for the organization. Studies conducted to find the "most appropriate leadership behavior showed that it impacts productivity with satisfaction from the team members" (Johns and Moser, 2001). Leadership faces considerable challenges to maintain job-centered and employee's-relationship due to the inverse relationship between these two factors. Michigan studies have found that employee-oriented leadership style is an effective behavior. Future research can conduct, whether any possible impact on productivity keeps both factors at a moderate level.

\subsection{Blake and Mouton Managerial Diagram Model (Managerial Grid)}

The managerial grid has concluded that the most effective leadership is team management as it is more concerned for people and results at the highest levels. Blake and Mouton have developed the managerial grid from the combination of Ohio State leadership studies and Michigan University studies. "Different leadership styles have been developed depending on different combinations of two leadership behaviors" (Daft et al., 2010). The following diagram model figure 4 shows four levels of the managerial grid.

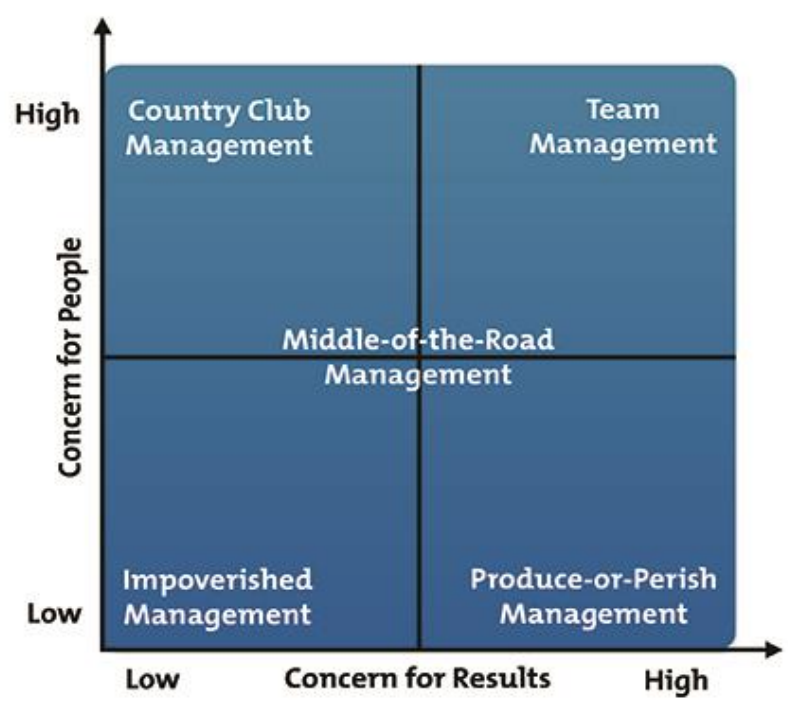

Figure 4. Showing the different levels of leadership behaviors

Source: https://www.mindtools.com/pages/article/newLDR_73.htm February 6, 2021

The above managerial grid has indicated that five leadership levels are based on the concerns of results and people. The behavioral theories have not considered the cultural values of individual levels of maturity, acceptance, and on the task. "Leadership effectiveness can be affected by several environmental factors" (Yuki, 1989). The main criticism on the managerial grid is based on organizational management than leadership qualities.

\section{Contingency Theories}

The emergence of contingency theories was developed based on the weaknesses of the great man theory, trait theory, and behavioral theories. The requirement of different leadership styles is based on different situations, so effective leadership style has to change in line with environmental factors or according to the situation. The situational theories emphasize that leadership behaviors need to be adjusted based on the case to the situation. Therefore, contingency theory states that the person performs an effective leadership style for a particular situation or conditions but is not effective in other various conditions or circumstances. A leadership style that was effective in the past was not effective (Fiedler, 2006). Studies have concluded that in any cases, there are no ideal leadership styles. The traditional leadership theories have been obsoleted, and the leaders have to create new styles to adopt the modern leadership style in line with the global pandemic situation. The study state, "it is possible to talk about many factors that make leadership effective" (Kraft, 2018). The situational factors depend on the nature and experiences of the leadership qualities, group or team member's qualities, organizational structure, and some other factors. 
The studies of contingency theories tried predicting "which type of leadership style will be most effective in different types of situations" (Holda, 1995). There is no acceptable leadership style globally at present. "Leadership must change with the situation or the situation must change to accommodate the type of leadership exercised" (Fairholm, 1998). Leadership has variables, so the effective leader can select the appropriate leadership style that suits that environment. The main criticism of contingency theory is the complexity and the lack of flexibility. In this regard, "the effective way to handle different situations is to change leadership style as flexible leaders bring more chaos and unstable situation in the organization" (Bastian \& Wald, 2012). The contingency theory lacks adequate research, and the outcome of the study has failed to explain how certain leadership qualities influence followers' human relations (Shonhiwa, 2016). However, contingency theories remain an effective leadership theory in the current context.

\subsection{Fiedler's Contingency Theory}

The relationship between the leader and team is to be in the good term, the jobs are well planned or wellstructured and the leadership position's power is at the highest level (Figure 5). Therefore, the most effective leadership can be task-motivated leadership. Still, task-motivated leadership can be applied when the relationship between the leader and team is at a weak level and is unplanned with the leadership position's power when at the lowest level.

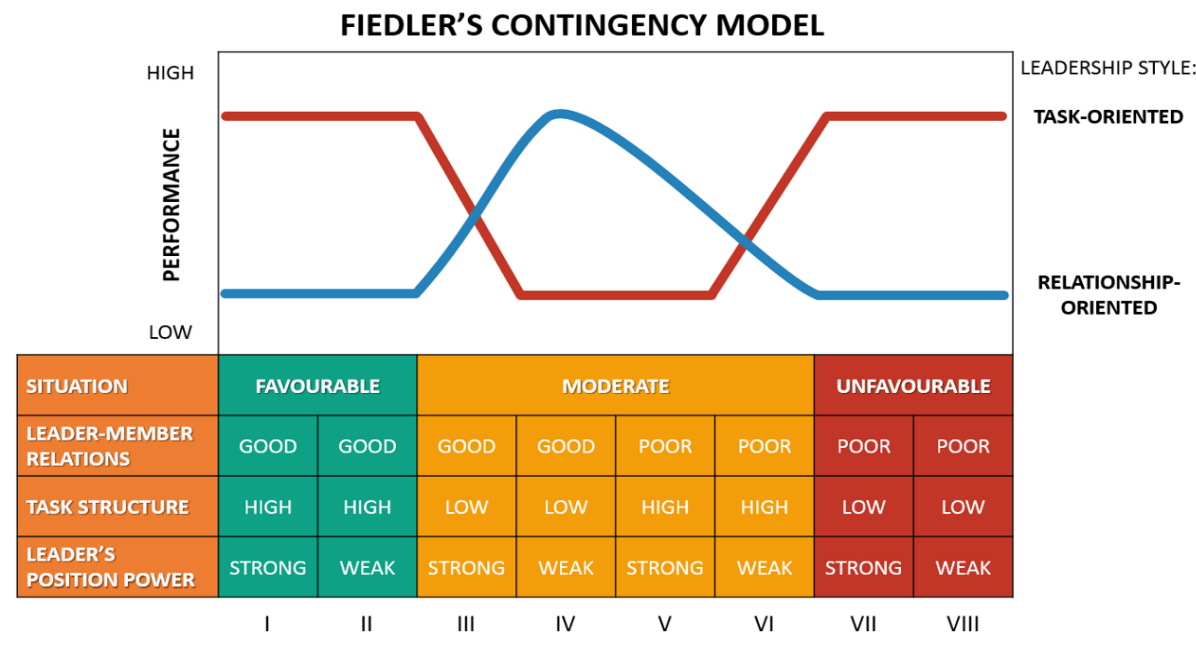

Figure 5. Fiedler's Contingency Model

Source: https://www.mindtools.com/pages/article/newLDR_73.htm February 4, 2021

Effective leadership is based on contingencies (Fiedler, 1975). Fiedler has raised questions that a person with the same qualification can be the best leader in a particular situation, but another person with the same qualification cannot be the best leader in the same situation. Motivated leadership relationship shall be applied at the moderate level of the leaders-follower relations, leader's position power, and task planning. The main criticism of Fiedler's contingency model outcome is unreliable, and leadership cannot be measured. As a result, future studies shall conduct Fiedler's contingency model with leadership measurement scales.

\subsection{Hersey Blanchard's Model}

Hersey Blanchard's Model is developed based on the behavioral theory by an extension of the maturity dimension. This model has included relationship-oriented, task-oriented, and the maturity of followers. Hersey Blanchard's model, determining leader behavior's appropriateness, is "based on the maturity of followers" (Daft et al., 2010). The maturity dimension excludes age and emotional intelligence, whereas it included a commitment for success, competencies, and life-long experience of team members or followers. This study was conducted based on the two factors, psychological and work maturity. Psychological maturity is related to the followers' willingness to work; work maturity is related to the follower's skills and competencies (Cherry, 2018; Graeff, 1983). If the follower's "maturity level is moderate, effective leadership styles are selling and participating styles" (Cherry, 2018). The effective leadership style depends on team members' willingness, where the leader has to adjust behaviour based on team member's maturity. 


\begin{tabular}{|c|c|c|c|c|}
\hline Maturity levels & Follower behaviors & $\begin{array}{c}\text { Psychological and Work } \\
\text { Maturity }\end{array}$ & Leadership styles & Leadership behavior \\
\hline Mature & Willing Can & $\begin{array}{c}\text { Psychological maturity (+) } \\
\text { Work Maturity (+) }\end{array}$ & $\begin{array}{c}\text { Delegating: Planning and } \\
\text { execution authorities are } \\
\text { given to followers }\end{array}$ \\
\hline Moderate & Willing Can not & $\begin{array}{c}\text { Psychological maturity (+) } \\
\text { Work Maturity (-) }\end{array}$ & $\begin{array}{c}\text { Participating: Leader } \\
\text { includes followers in } \\
\text { decision-O making }\end{array}$ \\
\hline Moderate & Unwilling Can & $\begin{array}{c}\text { Psychological maturity (-) } \\
\text { Work Maturity (+) }\end{array}$ & $\begin{array}{c}\text { Selling: Leader explains } \\
\text { ideas to followers }\end{array}$ & $\begin{array}{c}\text { High R-O } \\
\text { High T-O }\end{array}$ \\
\hline Immature & Unwilling Can not & $\begin{array}{c}\text { Psychological maturity (-) } \\
\text { Work Maturity (-) }\end{array}$ & $\begin{array}{c}\text { Telling: The Leader gives } \\
\text { orders to followers }\end{array}$ \\
\hline
\end{tabular}

Figure 6. Hersey-Blanchard Situational Leadership Model

$R-O$ : Relationship oriented T-O: Task oriented

Source: Uslu, O. (2019). A general overview to leadership theories from a critical perspective. Marketing and Management Innovations, 161-172.

\subsection{Path-Goal Theory}

The Path-Goal theory developed by Robert House (1971) was based on the expectation theory (Gordon, 1991). The Path-Goal theory has found two central leaderships such as directives and support. Both leaderships can create job satisfaction and performance as long as it is structured and planned well. The theory has been developed based on motivation and performance factors. Figure 7 explains four leadership styles: Directing, Coaching, Supporting, and Delegating. Effective leaders can "reward the followers when the set goal is achieved" (House, 1971). The followers should have a clear understanding of the goal and know the path to achieve it.

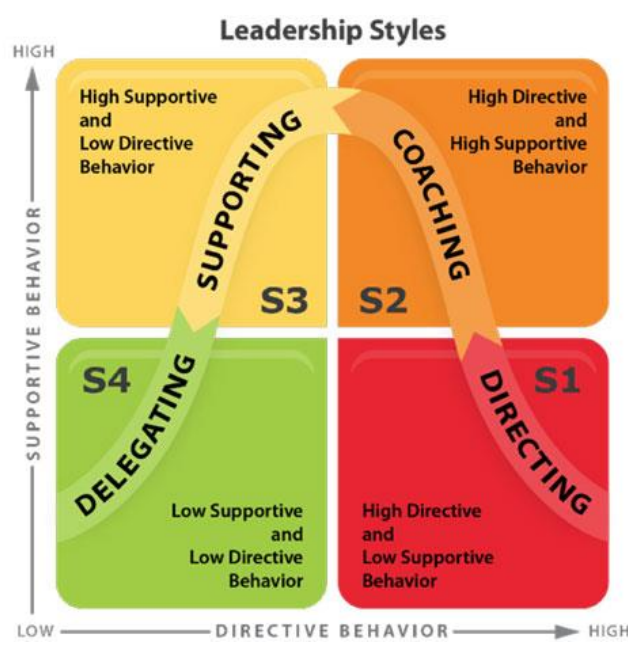

Figure 7. Path-Goal Theory

Source: https://www.zkg.de/en/artikel/zkg_Cutting-edge_classic_Situational_Leadership_2648579.html accessed February 20,2021

\section{Results and Discussion}

The three main leadership theories were critical analyses in all aspects with support from various scholars. Different leadership studies have emerged in different periods based on the increased demand in the competitive business environment. Thus, each study merits and demerits based on different perspectives, so the accepted universal leadership has not yet been developed. However, it is a challenging and exciting topic in the studies. A critical view of leadership theories has concluded that the literature review in the leadership theories can be enlightened.

\section{Conclusions}

The three main leadership theories have been discussed and criticized in the above study. The great man theory is the first leadership theory. It is concerned with the trait theory since both approaches have similarities in terms of assumptions. Great man theory revealed that "the characteristics of a leader are innate" (Kirkpatrick and Locke, 1991); trait theory claims that "the leader's characteristics can both innate and subsequently acquired" (Pierce and Dunham, 1990). This assumption indicates that the great man theory and trait theory are distinct from each other. The main criticism of the great man theory is "gender-based on prejudice" (Spector, 2016). This theory emphasized male dominance culture since its early leadership stage as women were not involved in the leadership role. In the current COVID-19 context, women's leadership is more appropriate, and more 
consultative is requesting to understating people's needs and wants. Trait theory and the great man theory had a lack of inconsistent scientific results. The behavioral theory has emerged due to the criticisms of the previous two approaches. The behavioral theory has developed based on the two factors: task-oriented and relationshiporiented. The environmental or situational factors have not been considered in the great man theory, trait theory and behavioral theory. The emergence of contingency theory has overcome weaknesses in the previous leadership theories. These theories were developed based on the North American origin and culture value where the validity of the theory in all parts of the globe is suspicious (Pasa et al., 2001). The perception, attitudes, cultural values of North America is not the same as the rest of the world, so the contingency theory is doubtful. The leadership style varies from culture to culture, situational to situational, western to eastern as they are all not the same. As a result, the leadership "theoretical integration has yet to be completed" (Avolio, 2007; Deure et al., 2011). Future research can explore leadership theories that can be integrated and developed into a single leadership management theory. New leadership theories are emerging every day, but have failed to bring a new set of leadership styles. Nevertheless, repeating the previous leadership theories from a different perspective. The post-COVID-19 has been an emerging leadership style on adaptability in a remote environment. The postCOVID-19 global pandemic has created a new leadership style called resilience leadership. Therefore, the global pandemic has created a leadership challenge in the 21 st century.

Funding: There is no funding for this research.

\section{References}

1. Avolio, B.J. (2007). Promoting more integrative strategies for leadership theory - building. American Psychologist. DOI:10.1037/0003-066X.62.1.25.

2. Barling, J., Christie, A., \& Hoption, C. (2011). Leadership. In S. Zedeck (Ed.), APA handbook of industrial and organizational psychology, Vol. 1, Building and developing the organization. American Psychological Association. https://doi.org/10.1037/12169-007.

3. Bartol, K., \& Martin, D. (1998). Management, $3^{\text {rd }}$ Ed., USA, McGraw - Hill Companies Inc. Available at: https://www.worldcat.org/title/management/oclc/715919148.

4. Bass, B. (1990b). From Transactional to Transformational Leadership: Learning to share the vision. Organizational Dynamics, 18(3), 19-31. https://doi.org/10.1016/0090-2616(90)90061-S.

5. Bastian, H., \& Wald, A. (2012). A bibliometric view on the use of contingency theory in project management research. Project Management Journal, 43(2), 5-20. https://doi.org/10.1002\%2Fpmj.21267.

6. Bennis, W.G. (2007). The challenges of leadership study in the modern world - Introduction to the special issue. American Psychologist. https://doi.org/10.1037/0003-066X.62.1.2.

7. Billing, M. (2015). Kurt Lewin's leadership studies and his legacy to social psychology: Is there nothing as practical as a good theory? Journal for the Theory of Social Behavior, 45(4). https://doi.org/10.1111/jtsb.12074.

8. Bryman, A. (1986). Leadership and Organisations. Boston, MA: Routledge \& Kegan Paul. 235 p. Available at: https://pdfslide.net/documents/leadership-and-organizations-a-bryman-routledge-kegan-paul-london1986.html.

9. Cherry, K. (2018). Situational leadership theory. Available at: https://www.Verywellmind.com/what-isthe-situational-theory-of-leadership-2795321.

10.Daft, R. (1999). Leadership Theory and practices. Fort Worth, TX: Dryden Press. 496 p. Available at: https://www.worldcat.org/title/leadership-theory-and-practice/oclc/40461786.

11.Fiedler, F. (1975). The leadership game, matching the man to the situation. Organisational Dynamics, 6-16. Available at: https://www.sciencedirect.com/science/article/abs/pii/0090261676900322.

12.Fiedler, F.E. (2006). The contingency model: a theory of leadership effectiveness, In Levine, J.M. \& Moreland, R.L.(Eds.), Small Groups Key Realigns, Psychology Press, New York. Available at: https://www.taylorfrancis.com/chapters/reading-20-contingency-model-theory-leadership-effectivenessfred-fiedler/e/10.4324/9780203647585-33.

13.Fleeor. J. W. (2006). Trait approach to leadership. Encyclopedia of Industrial and Organisational Psychology, Thousand Oaks, Sage Publications. 830-832. Available at: https://www.academia.edu/15810226/Trait_Approach_to_Leadership.

14.Gardner, J. (1990). On Leadership. New York: Free Press. 220 p. Available at: https://www.worldcat.org/title/on-leadership/oclc/20013777.

15.Gordon, J.R. (1991). A Diagnostic Approach to Organizational Behaviour. Allyn and Bacon, USA. 779 p. Available at: https://www.biblio.com/book/diagnostic-approach-organizational-behavior-judith$\underline{\mathrm{r} / \mathrm{d} / 1234564117 .}$ 
16.Graeff, C.L. (1983). The situational leadership theory: a critical view. Academy of Management Review. https://doi.org/10.5465/amr.1983.4284738.

17.Griffin R.W. (1990). Management, $3^{\text {rd }}$ Edition, Houghtion Miffin Company, Boston, USA. 884 p. Available at: https://psycnet.apa.org/doi/10.2307/257756.

18.Harrison, C. (2018). Leadership theory and Research. Palgrave Macmillan, Cham. 128 p. https://doi.org/10.1007/978-3-319-68672-1.

19.Holda, W. (1995). Leader - follower congruence: An analysis of community college presidential leadership, $\mathrm{PhD}$ dissertation, Texas $\mathrm{A} \& \mathrm{M}$ University at Commerce. Available at: https://core.ac.uk/download/pdf/4268413.pdf.

20.Hughes, T. (2005). Identification of Leadership style of enrollment management professionals in PostSecondary Institutions in the southern United States, Ph.D. dissertation, Texas Tech. University. Available at:https://media.proquest.com/media/pq/classic/doc/4327168049/fmt/ai/rep/NPDF?_s=6eV615SDki8hbeU 0BkyriYM4OVQ\%3D.

21.Johns, H.E., \& Moses, H.R. (2001). From trait to transformation: the evolution of leadership theories. Education, 110(1), 115-122.

Available at: $\quad$ https://www.psycholosphere.com/From\%20trait\%20to\%20transformation\%20\%20The\%20evolution\%20of\%20leadership\%20theories\%20by\%20Johns\%20\&\%20Moser.pdf.

22.Judge, T.A., Bono, J.E., Ilies, R., \& Gerhardt, M.G. (2002). Personality and leadership: A qualitative and quantitative review. Journal of Applied Psychology, 87(4), 765-780. https://doi.org/10.1037/00219010.87.4.765.

23.Kirkpatrick, S.A., \& Locke, E.A. (1991). Leadership: Do traits matter? Academy of Management Perspectives, 5(2), 48-60. https://doi.org/10.5465/AME.1991.4274679.

24.Kraft, M.H.G. (2018). Antecedents and Perspectives of Ambidextrous Leadership. Marketing and Management of Innovations, 4, 5-13. http://doi.org/10.21272/mmi.2018.4-01.

25.Leftwich, P. (2001). Transformational Leadership at the Department Chair level in North Carolina Community Colleges, Ph.D. dissertation, North Carolina State University. Available at: https://eric.ed.gov/?id=ED457938.

26.Northhouse, P.G. (2010). Leadership: Theory and Practice ( $5^{\text {th }}$ Ed.). Thousand Oaks: CA; Sage. 456 p. ISBN: 0-8077-4679-7.

27.Pierce, J.L., \& Dunham, R.B. (1990). Managing Scott, Foresman/Little, Brown Higher Education, London, England. 591 p._Available at: https://www.worldcat.org/title/management/oclc/301365777.

28.Shonhiwa, D.C. (2016). An Examination of the situational leadership approach: Strengths and weaknesses. Cross - Currents. International Peer-Reviewed Journal on Humanities \& Social Sciences, 2(2), 35-40. https://doi.org/10.19030/jdm.v13i2.10218.

29.Stogdill, R.M. (1974). Handbook of Leadership: A survey of the literature, New York, Free Press. 581 p. https://doi.org/10.1177\%2F002194367501200210.

30.Uslu, O. (2019). A general overview to leadership theories from a critical perspective. Marketing and Management of Innovations, 1, 161-172. http://doi.org/10.21272/mmi.2019.1-13.

31.Yukl, G. (2002). Leadership in Organizations. $5^{\text {th }}$ ed. - International, Prentice Hall, Upper Saddle River, N.J. 528 p. Available at: http://www.mim.ac.mw/books/Leadership\%20in\%20Organizations\%20by\%20Gary\%20Yukl.pdf.No1fv HJjqGHg1RgmjuyjD0oYNhx7MNeo.

32.Wallace, M., \& Weese, W. (1995). Leadership, organizational culture, and Job Satisfaction in Canadian YMCA organizations. Journal of Sport Management, 9(2), 182-193. https://doi.org/10.1123/JSM.9.2.182.

33.Zacccaro, S.J. (2007). Trait-Based Perspectives of Leadership. American Psychologist, 62(1), 6-16. https://doi.org/10.1037/0003-066X.62.1.6. 